Bangl. J. Vet. Med. (2011). 9(1): $79-83$

\title{
COMPARATIVE EVALUATION OF COMMERCIAL SERODIAGNOSTIC TESTS FOR THE SEROPREVALENCE STUDY OF BRUCELLOSIS IN STRAY DOGS IN BANGLADESH
}

\author{
B. C. Talukder, M. A. Samad* and A K M A Rahman \\ Department of Medicine, Faculty of Veterinary Science, Bangladesh Agricultural University, \\ Mymensingh-2202, Bangladesh
}

\begin{abstract}
A prospective study of Brucella sero-prevalence was conducted in 30 stray dogs in Mymensingh Municipal Corporation area of Bangladesh during the period from January to December 2009. All the sera were screened primarily by Rose Bengal Plate Test (RBPT). Positive, doubtful and negative serum samples were further confirmed with Slow Agglutination Test (SAT), Standard Tube Agglutination Test (STAT) and indirect Enzyme Linked Immunosorbent Assay (ELISA) and all the SAT, STAT and ELISA negative samples were confirmed as negative. The sensitivity of RBPT, SAT and STAT was found to be of $100 \%, 66.67 \%$ and $66.67 \%$ with considering ELISA as a standard test while specificity was found to be of $96.29 \%$, $100 \%$ and $100 \%$ in stray dogs. This indicates that the SAT and STAT are found more specific than RBPT. Evaluation of comparison of sero-prevalence rates of canine brucellosis with the four sero-tests advocated to use ELISA for diagnosis of canine brucellosis. The overall sero-prevalence of canine brucellosis was recorded as $13.33 \%, 6.67 \%, 6.67 \%$ and $10.0 \%$ with RBPT, SAT, STAT and ELISA, respectively. Sero-results have analyzed on the basis of two age groups (up to 6 months and 7 to 36 months) and sex (male and female). Significantly $(\mathrm{p}<0.01)$ higher sero-prevalence rate of canine brucellosis was recorded in stray dogs aged between 7 to 36 months $(14.81 \%, 7.40 \%, 7.40 \%$ and $11.11 \%)$ in comparison to aged group up to 6 months $(0 \%, 0 \%, 0 \%$ and $0 \%)$ with RBPT, SAT, STAT and ELISA, respectively. The sero-prevalence rate of canine brucellosis was found significantly $(\mathrm{p}<0.01)$ higher in female dogs $(15.78 \%, 10.52 \%, 10.52 \%$ and $15.78 \%)$ in comparison to male $(9.09 \%, 0 \%, 0 \%$ and $0 \%)$ with RBPT, SAT, STAT and ELISA, respectively. It appears from this study that brucellosis is an endemic disease and measures are needed to reduce this high prevalence of canine brucellosis in Bangladesh.
\end{abstract}

Key words: Sero-prevalence, brucellosis, stray dogs, RBPT, SAT, STAT, ELISA

\section{INTRODUCTION}

Brucellosis is a global zoonotic disease, caused by Brucella spp. in several animal species and in humans. The most clinically relevant Brucella species, Brucella abortus, B. melitensis, B. canis and B. suis, tend to be hostadapted, although infections of other animal species, including humans, may occur sporadically (Samad, 2008). Canine brucellosis is usually caused by $B$. canis, although $B$. abortus, B. suis, B. melitensis also produce disease when dogs eat placentas from animals (Samad, 2008). There are reported evidence that Brucella transmit from cattle to dog and this dog play a possible role as vector (Prior, 1976; Bicknell and Bell, 1979). The B. melitensis is considered the most virulent species for humans, followed by B. suis and B. abortus in that order. The clinical infection with $B$. canis caused abortion and infertility in female dogs, epididymitis and testicular atrophy in male dogs and generalized lymphadenitis in both (Dunne et al., 2002). Because the disease develops asymptomatically in dogs and gives uncertain clinical signs, laboratory tests are very important for the diagnosis is usually accomplished by isolation of the causative agent but cultivation is time-consuming and fastidious as members of the genus Brucella do not grow easily. Accordingly, serological diagnostic techniques have been developed to overcome the limits of bacterial isolation. Several serological assays are commercially available for rapid diagnosis of brucellosis which is especially important in order to isolate infected dogs and prevent secondary infections of susceptible animals. The Rose Bengal Plate Test (RBPT), Slow Agglutination Test (SAT), Standard Tube Agglutination Test (STAT) and Enzyme Linked Immunosorbent Assay (ELISA) are commercially available serological methods for the diagnosis of brucellosis. Several researchers have reported rates of seroprevalence ranging between 2 and 30\% in dogs in various countries of the world (Boebel et al., 1979; Mosallanejad et al., 2009). The sero-prevalence of brucellosis in food animals (Mustafa, 1984; Rahman and Mia 1970; Rahman and Rahman 1981; Rahman et al., 1978; 1983; 1988; 1997; 2006; Uddin and Rahman 2007) and

*Corresponding e-mail address: masamad88bau@yahoo.com 


\section{B.C. Talukder and others}

humans (Rahman et al., 1983; Rahman et al., 1988) have been reported from Bangladesh but similar seroprevalence reports on canine brucellosis are not available under local conditions. This paper describes the seroprevalence of brucellosis in stray dogs detected by using four sero-tests in Bangladesh.

\section{MATERIALS AND METHODS}

A total of 30 street dogs were caught with the help of Municipal Corporation of Mymensingh district during the period of January to December 2009. All the dogs caught for euthanasia were first examined the external appearance. The data about the sex and age of all the randomly selected dogs were collected by through examination of each of the dogs. The animals were controlled by locally prepared mechanical device and about $10 \mathrm{ml}$ of blood was drawn directly from the left ventricle of heart with the help of sterile syringe and needle. During collection of blood all precaution were taken to avoid hemolysis. The collected blood was immediately transferred to the collecting test tubes and allowed to clot undisturbed at the room temperature for half an hour in the laboratory and later were kept overnight at $4{ }^{\circ} \mathrm{C}$ in refrigerator. Then the sera were separated in the next day by centrifugation at $3000 \mathrm{rpm}$ for 10 minutes and the sera were stored at $-20^{\circ} \mathrm{C}$ until tested.

Each of the collected serum samples was tested with RBPT, STAT, SAT and ELISA as per the manufacturer's instruction. The RBPT antigen (Veterinary Laboratory Agency, UK) prepared by a heat killed stained suspension of Brucella melitensis S99). The Brucella STAT antigen (Cypress Diagnostics, Belgium) was used for this test. The SAT (Symbiotic, concentrated suspension of Brucella abortus Weybridge, strain 99) was carried out with EDTA as described by Garin et al. (1985).

\section{Statistical analysis}

Test results and potential association with age, sex and among tests were performed by SPSS 10.0 for Windows using Fisher's exact test and Chi-square analysis.

\section{RESULTS AND DISCUSSION}

Brucellosis is a widespread and an important reproductive disease of animals and remains a major zoonosis (WHO, 2006). The sero-prevalence of brucellosis in food animals (Rahman and Mia 1970; Rahman and Rahman, 1981; 1982; Pharo et al., 1981; Rahman et al., 1978; 1983; 1997; 1988; 2006; Islam et al., 1983, 2007; Mustafa, 1984; Ahmed et al., 1992; Amin et al., 2005; Uddin and Rahman 2007) and humans (Rahman et al., 1983; 1988; Muhammad et al., 2010; Nahar and Ahmed 2009) have been reported from Bangladesh. These results indicate that brucellosis is an endemic disease in food animals and humans in Bangladesh. This study is the first report on the sero-prevalence of brucellosis in stray dogs of Bangladesh by using four commercial sero-diagnostic kits.

Sensitivity of RBPT, SAT, STAT was found to be of $100 \%, 66.67 \%$ and $66.67 \%$ with considering ELISA as a gold standard test while specificity was found to be of $96.29 \%, 100 \%$ and $100 \%$ in stray dogs (Table 1). It appears that SAT and STAT is found more specific than RBPT.

Serum samples of 30 stray dogs were tested by the commercial diagnostic test kits of RBPT, SAT, STAT and indirect ELISA and their results are presented in Table 2. The sero-prevalence of canine brucellosis detected by using RBPT, SAT, STAT and ELISA showed $13.33 \%(\mathrm{n}=4), 6.67 \%(\mathrm{n}=2), 6.67 \%(\mathrm{n}=2)$ and $10.0 \%(\mathrm{n}=3)$, respectively. It appears that the highest sero-prevalence of canine brucellosis was recorded with RBPT (13.33\%) and the lowest sero-prevalence with SAT (6.67\%) and STAT (6.67\%). These sero-positivity results were considered Brucella infection due to natural infection because vaccination has never been practiced in Bangladesh.

The highest sero-prevalence of canine brucellosis was recorded with RBPT (13.33\%) in comparison to SAT (6.67\%) and STAT (6.67\%). These sero-prevalence results correlate with the report of Zivojinovic et al. (2006) who reported $16.55 \%$ and $11.25 \%$ sero-positivity with Rapid agglutination test and Slow agglutination test, respectively in stray dogs. 
Table 1. Sensitivity and specificity of RBPT, SAT and STAT by comparing with ELISA for detection of Brucella antibodies in stray dogs

\begin{tabular}{|c|c|c|c|c|c|c|c|}
\hline \multirow[t]{2}{*}{$\mathrm{S} / \mathrm{N}$} & \multirow[t]{2}{*}{ Test used } & & \multicolumn{2}{|c|}{ ELISA } & \multirow[t]{2}{*}{ Total } & \multirow{2}{*}{$\begin{array}{l}\text { Sensitivity } \\
(\%)\end{array}$} & \multirow{2}{*}{$\begin{array}{l}\text { Specificity } \\
(\%)\end{array}$} \\
\hline & & & Positive & Negative & & & \\
\hline \multirow{3}{*}{ (1) } & \multirow{3}{*}{ RBPT } & Positive & 3 & 01 & 04 & \multirow{3}{*}{100} & \multirow{3}{*}{96.29} \\
\hline & & Negative & 0 & 26 & 26 & & \\
\hline & & Total & 3 & 27 & 30 & & \\
\hline \multirow[t]{3}{*}{ (2) } & \multirow[t]{3}{*}{ SAT } & Positive & 2 & 00 & 02 & \multirow{3}{*}{66.67} & \multirow{3}{*}{100} \\
\hline & & Negative & 1 & 27 & 28 & & \\
\hline & & Total & 3 & 27 & 30 & & \\
\hline \multirow[t]{3}{*}{ (3) } & \multirow[t]{3}{*}{ STAT } & Positive & 2 & 00 & 02 & \multirow{3}{*}{66.67} & \multirow{3}{*}{100} \\
\hline & & Negative & 1 & 27 & 28 & & \\
\hline & & Total & 3 & 27 & 30 & & \\
\hline
\end{tabular}

RBPT $=$ Rose Bengal Plate Test

SAT $=$ Slow Agglutination Test

STAT $=$ Standard Tube Agglutination Test

ELISA = Enzyme Linked Immunosorbent Assay

Comparative evaluation of indirect ELISA with RBPT, SAT and STAT positive and suspicious sera ensured a very high sensitivity and specificity. Sensitivity of RBPT, SAT and STAT was found to be of $100 \%, 66.67 \%$ and $66.67 \%$ with considering ELISA as a standard test while specificity was found to be of $96.29 \%, 100 \%$ and $100 \%$ in stray dogs (Table 1). Therefore, SAT and STAT were found more specific than RBPT. It appears that RBPT could be used as a screening test for brucellosis due to its low cost and easy execution. The ELISA would provide better estimates of the actual prevalence of the infection as has been reported by Taner et al. (2005).

Table 2. Age, sex and sero-test-wise sero-prevalence of brucellosis in stray dogs; No. + ve (\%)

\begin{tabular}{|c|c|c|c|c|c|c|}
\hline \multirow[t]{2}{*}{$\mathrm{S} / \mathrm{N}$} & \multirow[t]{2}{*}{ Test used } & \multicolumn{2}{|c|}{ Age (months) } & \multicolumn{2}{|c|}{ Sex } & \multirow{2}{*}{$\begin{array}{l}\text { Overall } \\
(\mathrm{n}=30)\end{array}$} \\
\hline & & $1-6$ & $7-37$ & $\begin{array}{l}\text { Male } \\
(n=11)\end{array}$ & $\begin{array}{l}\text { Female } \\
(n=19)\end{array}$ & \\
\hline (1) & RBPT & $0(0.00)$ & $4(14.81)^{*}$ & $1(9.09)$ & $3(15.78)^{*}$ & $4(13.33)$ \\
\hline (2) & SAT & $0(0.00)$ & $2(07.40)^{*}$ & $0(0.00)$ & $2(10.52)^{*}$ & $2(06.67)$ \\
\hline (3) & STAT & $0(0.00)$ & $2(07.40)^{*}$ & $0(0.00)$ & $2(10.52)^{*}$ & $2(06.67)$ \\
\hline (4) & ELISA & $0(0.00)$ & $3(11.11)^{*}$ & $0(0.00)$ & $3(15.78)^{*}$ & $3(10.00)$ \\
\hline
\end{tabular}

$\begin{array}{lll}\text { RBPT }=\text { Rose Bengal Plate Test } & \text { SAT }=\text { Slow Agglutination Test } & * \text { Significant }(\mathrm{p}<0.01) \\ \text { STAT }=\text { Standard Tube Agglutination Test } & \text { ELISA }=\text { Enzyme Linked Immunosorbent Assay } & \end{array}$

The indirect ELISA has detected $10 \%$ sero-prevalence rate of brucellosis in stray dogs which supports the earlier reports of Radojivic et al. (2001) who reported $9.37 \%$ and $10.87 \%$ sero-prevalence of brucellosis in stray dogs of Podgoria and Belgrade, respectively. However, higher (Diker et al., 1987; Molnar et al., 2001; KhairaniBejo and Bahaman, 2006) and lower (Myers and Varela-Diaz, 1980; Baldi et al., 1994; Taner et al., 2005) seroprevalence rates of brucellosis have been reported in unattended dogs elsewhere. 


\section{B.C. Talukder and others}

Analysis of sero-results on the basis of two age groups (up to 6 months and 7 to 36 months) showed that all the dogs up to 6 months of age were found negative to all the used four sero-tests. Of the 24 stray dogs aged between 7 to 36 months tested with RBPT, SAT, STAT and ELISA, of which 4 (14.81\%), $2(2.40 \%), 2(2.40 \%)$ and 3 $(11.11 \%)$ dogs showed positive reaction to brucellosis, respectively (Table 2). These results support the earlier report of Mosallanejad et al. (2009) who reported more Brucella infection in dogs above 5 years $(9.3 \%$; 4 of 43$)$ in comparison with dogs less than 5 years $(1.69 \%$; 1 of 59). These results indicate that the canine brucellosis is mainly prevalent in adult stray dogs. This shows that higher age may increase exposing probability to infection.

Sex-wise analysis of the sero-prevalence of brucellosis in stray dogs revealed that out of 11 male dogs, only one male dog showed positive reaction with RBPT (9.09\%), whereas of the 19 female dogs tested, of which 3 (15.78\%), 2(10.52\%), $2(10.52 \%)$ and $3(15.78 \%)$ were found positive with RBPT, SAT, STAT and ELISA, respectively (Table 2$)$. These sero-results indicate significantly $(\mathrm{p}<0.01)$ higher sero-prevalence of brucellosis in female than male dogs which are in conformity with that of Bigdeli et al. (2011) who reported higher seroprevalence of brucellosis in female than male dogs.

It may be concluded from the results of this study that stray dog population in Bangladesh may be considered as a carrier of Brucella infection and might act as a risk for food animal and human health. Therefore, further studies should be conducted on the sero-prevalence of canine brucellosis simultaneously with B. abortus and $B$. canis derived antigens in a large population of stray and pet dogs with isolation and characterization of the causative agent.

\section{REFERENCES}

1. Ahmed JU, Alam MGS, Rahman MM and Hossain M (1992). Seroprevalence of brucellosis in indigenous zebu cows of Bangladesh. Bangladesh Journal of Microbiology 9: 17-21.

2. Amin KMR, Rahman MB, Rahman MS, Han JC, Park JH and Chae JS (2005). Prevalence of Brucella antibodies in sera of cows in Bangladesh. Journal of Veterinary Science 6: 223-226.

3. Baldi PC, Wanke MM, Loza ME and Fossati CA (1994). Brucella abortus cytoplasmic proteins are used as antigens in an ELISA potentially useful for the diagnosis of canine brucellosis. Veterinary Microbiology 41 : 127-134.

4. Bicknell SR and Bell RA (1979). Brucella abortus in the bitch: sub-clinical infection associated with urinary excretion. Journal of Hygiene (London) 82: 249-254.

5. Bigdeli M, Namavari MM, Moazeni-Jula F, Sadeghzadeh S and Mirzae A (2011). First study prevalence of brucellosis in stray and herding dogs south of Iran. Journal of Animal and Veterinary Advances 10: 13221326.

6. Boebel FW, Ehrenford FA, Brown GM, Angus RD and Thoen CO (1979). Agglutinins to Brucella canis in stray dogs from certain countries in Illinois and Wisconsin. Journal of American Veterinary Medical Association 175: 276-277.

7. Diker KS, Aydin N, Erdeger J and Ozyuri M (1987). A serologic survey of dogs for Brucella canis and Brucella abortus and evaluation of mercaptoethanol microagglutination test. Ankara University of Veterinary Faculty Derg 34: 268-276.

8. Dunne J, Sehgal K, McMillan A and Perret L (2002). Canine brucellosis in a dog imported into the UK. Veterinary Record 151: 247.

9. Garin B, Trap D and Gaumont R (1985). Assessment of the EDTA seroagglutination test for diagnosis of bovine brucellosis. Veterinary Record 117: 444-445.

10. Islam MA, Haque M, Rahman A, Rahman MM, Rahman MA and Haque F (1983). Economic losses due to brucellosis among cattle in Bangladesh. Bangladesh Veterinary Journal 17: 56-62.

11. Islam MM, Siddiqui MAR, Haque MA, Baki MA, Majumder S, Parrish JJ and Shamsuddin M (2007). Screening some major communicable diseases of AI bulls in Bangladesh. Livestock Research for Rural Development 19: 1-9.

12. Khairani-Bejo S and Ardhy-Adman Bahaman AR (2006). Investigation of canine brucellosis in Klang Valley Malaysia. Journal of Animal Veterinary Advances 5: 42 - 44. 
13. Molnar L, Molnar E and Carvalho M (2001). Capacity of some serological tests for diagnosis of canine brucellosis. A Hora Veterinaria 21: 45-49.

14. Mosallanejad B, Ghorbanpoor NM, Avizeh R and Mohammadian N (2009). A serological survey on Brucella canis in companion dogs in Ahvaz. Iranian Journal of Veterinary Research, Shiraz University 10: $383-386$.

15. Muhammad N, Hossain MA, Musa AK, Mahmud MC, Paul SK, Rahman MA, Haque N, Islam MT, Parvin US, Khan SI, Nasreen SA and Mahmud NU (2010). Seroprevalence of human brucellosis among the population at risk in rural area. Mymensingh Medical Journal 19: 1-4.

16. Mustafa AH (1984). Brucella antibodies in the sera of domestic livestock in Bangladesh. Tropical Animal Health and Production 16: 212.

17. Myers DM and Varela-Diaz VM (1980). Serological and bacteriological detection of Brucella canis infection of stray dogs in Moreno, argentina. Cornell Veterinarian 70: 258-265.

18. Nahar A and Ahmed MU (2009). Sero-prevalence study of brucellosis in cattle and contact human in Mymensingh district. Bangladesh Journal of Veterinary Medicine 7: 00-00.

19. Pharo HJ, Motalib A, Alam S, Fraser GC and Routledge SF (1981). Preliminary information on the prevalence of bovine brucellosis in the Pabna Milk-shed area of Bangladesh. Bangladesh Veterinary Journal 15: 43-51.

20. Prior MG (1976). Isolation of Brucella abortus from two dogs in contact with bovine brucellosis. Canadian Journal of Comparative Medicine. 40: 117-118.

21. Radojivic S, Lako B, Uricic B and Valcic M (2001). Dot-ELISA as a rapid method for serological diagnosis of canine brucellosis. Acta Veterinaria Beograde 51: 317-324.

22. Rahman MA and Mia SA (1970). A study of brucellosis in Bangladesh. Bangladesh Journal of Animal Sciences 3: 39-44.

23. Rahman MM, Chowdhury TIMFR and Chowdhury MUA (1978). Investigation of brucellosis among cattle. Bangladesh Veterinary Journal. 12: 12-15.

24. Rahman MM and Rahman MA (1981). Incidence of Brucella infection in sub-clinical mastitic udder. Bangladesh Veterinary Journal 15: 39-42.

25. Rahman MM and Rahman MS (1982). Study on the prevalence of brucellosis in cows in organized farms and domestic holdings in Bangladesh. Bangladesh Veterinary Journal 16: 12-15.

26. Rahman MM, Chowdhury TIMFR, Rahman A and Haque F (1983). Seroprevalence of human and animal brucellosis in Bangladesh. Indian Veterinary Journal 60: 165.

27. Rahman MM, Haque M and Rahman MA (1988). Sero-prevalence of caprine and human brucellosis in some selected areas of Bangladesh. Bangladesh Veterinary Journal 22: 85-92.

28. Rahman MA, Islam MA, Alam MGS and Shamsuddin M (1997). Sero-prevalence of brucellosis in the buffalo (Bubalus bubalis) of a selected area in Bangladesh. Buffalo Journal 2: 209-214.

29. Rahman MS, Han JC, Park J, Lee JH, Eo SK and Chae JS (2006). Prevalence of brucellosis and its association with reproductive problems in cows in Bangladesh. Veterinary Record 159: 180-182.

30. Samad MA (2008). Animal Husbandry and Veterinary Science. Volume 2. $1^{\text {st }}$ Pub., LEP No. 11, BAU Campus, Mymensingh.

31. Taner O, Mehmet A, Baris SO, Yasar T and Alper C (2005). Sero-prevalence of Brucella canis infection of dogs in two provinces in Turkey. Turkey Journal of Veterinary and Animal Sciences 29: 779- 783.

32. Uddin MJ and Rahman MS (2007). Brucellosis of goat in Bangladesh. Journal of the Bangladesh Agricultural University 5: 287-294.

33. WHO (2006). Brucellosis in human and animals. Joint report of WHO, FAO and OIE, Rome.

34. Zivojinovic S, Radojicic S, Zivojinovic M and Kircanski J (2006). Investigations of spread of canine brucellosis caused by Brucella canis. Veterinarski Glasnik 60: 337-344. 